\title{
MYCORRHIZAL SPECIES DIFFERENTIALLY ALTER PLANT GROWTH AND RESPONSE TO HERBIVORY
}

\author{
Alison E. Bennett ${ }^{1}$ and James D. Bever \\ Department of Biology, Indiana University, 1001 E. 3rd Street, Bloomington, Indiana 47405 USA
}

\begin{abstract}
Plants simultaneously interact with multiple organisms which can both positively and negatively affect their growth. Herbivores can reduce plant growth through loss of plant biomass and photosynthetic area, while plant mutualists, such as mycorrhizal fungi, can increase plant growth through uptake of essential nutrients. This is the first study examining whether species-specific associations with mycorrhizal fungi alter plant tolerance to herbivory. We grew Plantago lanceolata plants with three species of mycorrhizal fungi previously shown to have differential impacts on plant growth and subjected them to herbivory by the specialist lepidopteran herbivore, Junonia coenia. Association with mycorrhizal fungus Glomus white provided the greatest growth benefit but did not alter plant response to herbivory. Alternatively, association with Archaeospora trappei provided less growth promotion but did lead to tolerance to herbivory in the form of an increased growth rate. Finally, an association with the fungus Scutellospora calospora led to neither plant growth promotion nor tolerance to herbivory. In fact, an association with $S$. calospora appeared to reduce plant tolerance to herbivory. An association with all three species of mycorrhizae resulted in a pattern of growth similar to that of plants grown only with Glomus white, suggesting that growth promotion by multiple mycorrhizal species is driven by the inclusion of a "super fungus," in this case, Glomus white. This work illustrates that plant response to herbivory depends upon the mycorrhizal fungal mutualist with which a plant is associated.
\end{abstract}

Key words: herbivory; Junonia coenia; multitrophic interactions; mycorrhizal fungi; nonadditive effects; Plantago lanceolata; resource allocation; sampling effect; tolerance.

\section{INTRODUCTION}

Plants simultaneously interact with multiple organisms which can both positively and negatively affect their growth. Herbivory, for example, can reduce photosynthetic area, plant fitness, alter plant allocation patterns, increase plant defenses, and even lead to plant death while mutualists such as mycorrhizal fungi can form symbiotic associations that often improve plant growth and survival. Moreover, plants may interact with multiple herbivores or mutualists at the same time. Individual plants, for example, may associate with many species of mycorrhizal fungi which differ greatly in their effect on plant growth (Bever 2002, Vandenkoornhuyse et al. 2003). The complexity of these interactions makes it difficult to predict plant response, or the response of plant mutualists, unless all the interactions are additive.

Plants associated with a single species of mycorrhizal fungi have demonstrated a wide array of growth responses (Smith and Read 1997), but what is the result of an association with multiple fungal species? Growth

Manuscript received 3 April 2006; revised 13 June 2006; accepted 13 June 2006. Corresponding Editor: J. N. Klironomos.

${ }^{1}$ Present address: 4348 Storer Hall, University of California, Davis, California 95616 USA.

E-mail: alibenne@bio.indiana.edu responses with multiple fungal species may be the average of growth promotion by each individual fungal species or may increase with each additional species of mycorrhizal fungi (van der Heijden et al. 1998) or they could be driven by the inclusion of a "super fungus" (Wardle 1999). To date, no study, to our knowledge, has attempted to separate these different potential mechanisms behind growth promotion of plants associated with multiple mycorrhizal fungal species.

In addition to altering plant growth responses, mycorrhizal fungi can alter plant responses to herbivory in a number of ways (Bennett et al. 2006). Mycorrhizal fungi may induce changes in plant quality, plant defenses, and plant tolerance (Bennett et al. 2006). However, understanding the mechanisms behind mycorrhizal fungal mediation of plant response to herbivory has been elusive, at best. For example, conflicting results have been reported for investigations of mycorrhizal fungal effects on plant tolerance. No tolerance (Borowicz 1997, Gange et al. 2002, Kula et al. 2005), tolerance (Gange et al. 2002, Kula et al. 2005), and increased tolerance (Kula et al. 2005) of plants associated with mycorrhizal fungi have been demonstrated within and between studies.

The conflicting effects of mycorrhizal fungal impacts on plant tolerance may result from the very different ecologies present among plant host species and mycor- 
rhizal fungal species. The host plant species used in the previous studies described above are all likely to vary in resource allocation patterns, growth, and tolerance, and this variation is likely to increase in the presence of different mycorrhizal mutualists. An examination of plants associated with three different species of the arbuscular mycorrhizal fungal genera Glomus revealed that plants demonstrated different growth patterns and received different herbivore loads in association with different fungal species (Gange et al. 2005), suggesting that individual mycorrhizal fungal species could effect plant responses to herbivory. Both herbivores (reviewed in Karban and Baldwin 1997) and mycorrhizal fungi (Bever 1994, Charron et al. 2001) have been shown to alter plant resource allocation to storage structures and roots. As a result, we would expect plants associated with mycorrhizal fungal partners to vary in tolerance, allocation to storage, and root to shoot ratios both in the absence and in the presence of herbivory.

The purpose of this study was twofold: we were interested first in whether plant response to herbivory depends upon the species of mycorrhizal fungi present and second in whether the plant response to individual mycorrhizal fungal species predicts the plant response to a community of mycorrhizal fungi. In order to test these questions we grew Plantago lanceolata with three species of mycorrhizal fungi (individually and in combination) that had previously been shown to vary in their effect on plant growth when associated with $P$. lanceolata, and subjected plants to herbivory by Junonia coenia larvae.

\section{Methods}

\section{Study system}

We examined Junonia coenia (also known as Precis coenia) butterflies feeding on Plantago lanceolata plants associated with three different arbuscular mycorrhizal fungal (AMF) symbionts. All three of these species (butterfly, plant, and fungi) coexist in the same old field on the Duke University campus in Durham, North Carolina, USA. Plantago lanceolata is a Eurasian weed widely distributed across the United States in old fields, mowed lawns, and disturbed sites. Junonia coenia, a native butterfly, feeds on members of the Plantaginaceae, and prefers to feed on Plantago lanceolata, because it contains the carbon-based secondary compounds derived from iridoid glycosides (commonly considered to be defensive chemicals; Duff et al. [1965], Bobbitt and Segebarth [1969]). Junonia coenia larvae sequester the iridoid glycosides found in plantain leaf tissues (Bowers and Puttick 1986, Bowers and Collinge 1992), and are thus considered specialists on this family.

Like many plants, Plantago lanceolata associates with arbuscular mycorrhizal fungi, mutualistic fungi that promote plant growth through the uptake of nutrients (particularly phosphorus) in return for carbohydrates from the plant. Over 37 species of arbuscular mycorrhizal fungi have been identified in the focal field at Duke University (Bever et al. 2001). We chose three species: an unidentified species of Glomus (referred to as Glomus d1 in Bever et al. [1996]) which we will refer to as Glomus white, Archeaespora trappei, and Scutellospora calospora. Bever (2002) demonstrated that Archaeospora trappei promotes Plantago lanceolata growth and Scutellospora calospora does not. However, Scutellospora calospora benefits from a higher population growth rate when grown with Plantago lanceolata.

\section{Experimental design}

We grew 70 Plantago lanceolata plants in five different fungal treatments (the fungi Glomus white, Archaeospora trappei, Scutellospora calospora individually, in combination, and a sterilized combination), and subjected the plants in half of each treatment to three rounds of $20 \%$ defoliation by Junonia coenia. Soil for the experiment was collected from the same old field near Duke University in North Carolina from which the $P$. lanceolata plants, the three mycorrhizal fungal species, and the Junonia coenia larvae were originally obtained. To promote drainage in pots, the soil was mixed 1:1 with sand and steam sterilized. Fungal inocula consisted of spores, hyphae, host-plant (Sorghum vulgare) roots, and soil and occupied one-sixth of the pot volume. Junonia coenia eggs and larvae were obtained from a colony maintained by Fred Nijhout at Duke University. Variation in plant response to herbivory is likely to vary due to both genetic and environmental factors, so we controlled for this natural variation using seeds from seven genotypes derived from mating parental genotypes of Plantago lanceolata gathered from the old field near Duke University. Genotypes were labeled A-G for clarity. Inoculum was obtained from individual pure cultures containing spores of Glomus white, Archaeospora trappei, and Scutelospora calospora maintained in the greenhouses on the campus of Indiana University.

Seeds from each genotype were germinated in sterile metromix (Scott's/Sierra Horticultural Company, Marysville, Ohio, USA), and following two weeks of growth, two seedlings from each genotype were transplanted separately into each fungal treatment. Five weeks following transplantation, plant size was determined by measuring the total leaf length of the plant. The final analysis of biomass and total leaf length revealed that total leaf length strongly predicts total plant size $\left(F_{1,91}=\right.$ $\left.5.75, R^{2}=0.9647\right)$. Plants were then subjected to three rounds (at weeks 5, 6, and 7) of $20 \%$ defoliation events by Junonia coenia larvae. We contained larvae within clip cages (petri dish lids held together by hair clips to form cages that easily open and close) during the duration of the herbivory events to insure that only $20 \%$ of the total leaf length was eaten, and empty clip cages were placed on uneaten plants to control for clip cage effects (see Plate 1). Beginning in week 13, plants were fertilized every other week with a 20:0:20 NPK fertilizer providing $0.333 \mathrm{~g}$ of elemental $\mathrm{N}$ and $\mathrm{K}$ per plant.

Total leaf length was measured at week 5 , week 6 , and week 7 to provide leaf lengths for each consecutive 


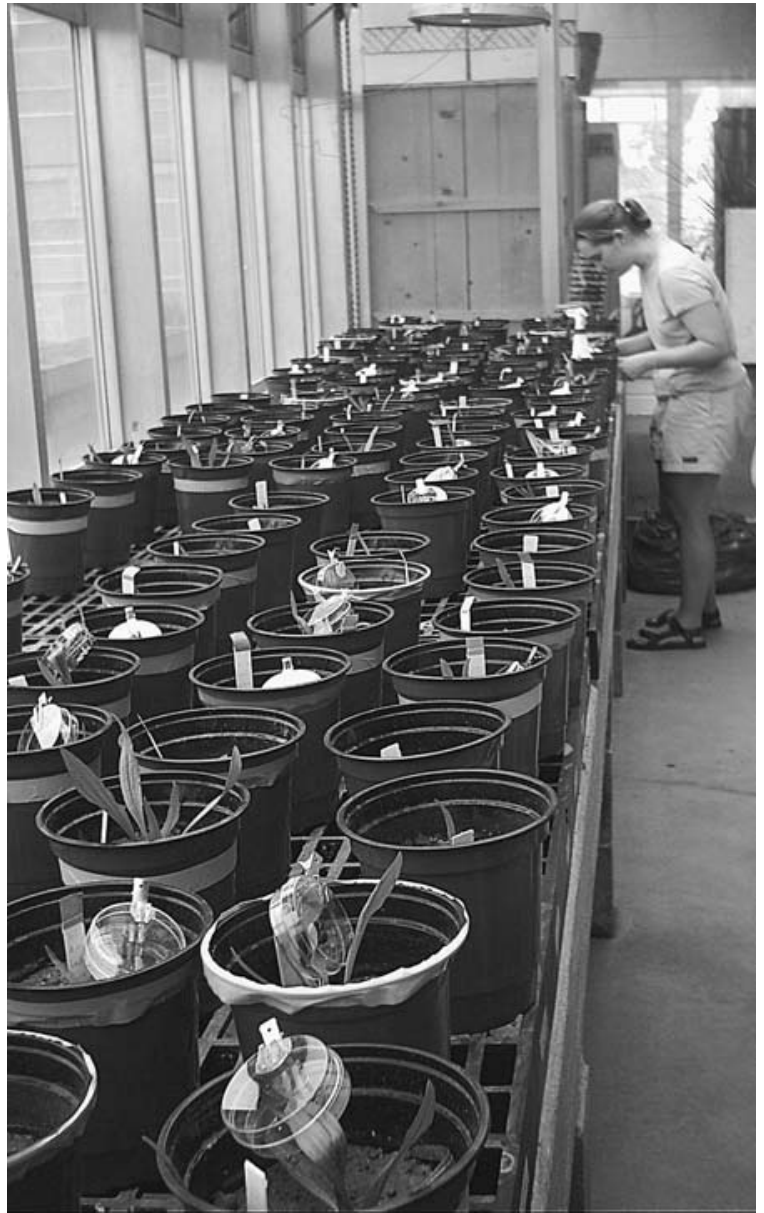

Plate 1. A. Bennett prepares insects and clip cages during herbivore induction. Photo credit: Julie Gummow.

herbivory event. In addition, total leaf length was measured at week 8, week 14, and week 20. After five months (week 20) of growth, plants were harvested for total, above-, and belowground biomass, reproductive biomass (defined as the stem and flower spike), and caudex biomass.

\section{Statistical analysis and interpretation}

Plant growth rate.-We analyzed two different measures of plant response: growth rate and final biomass. Total leaf length strongly predicts total plant size (see Methods: Experimental design). We calculated growth rate on a per leaf length basis as the difference in plant size at week 8 and plant size at week 20 divided by plant size at week 8 . Shifts in growth rate due to herbivory reflect tolerance to herbivory. We are particularly interested in whether plant tolerance depends on mycorrhizal fungal inoculation. We analyzed plant growth using a mixed-model ANOVA with genotype as a random effect within the general linear models procedure of SAS (SAS 2000). In this model, we tested for differences in growth between mycorrhizal fungal inoculation treatments using orthogonal a priori linear contrasts within herbivory and herbivory by inoculation terms. We decomposed the mycorrhizal fungal inoculation main effects and interactions into three orthogonal a priori contrasts: first, a comparison of growth without mycorrhizal fungi and the average of all mycorrhizal fungal inoculation treatments (live inocula vs. sterile inocula); second, an examination of additivity among mycorrhizal fungal species was tested as the difference between the three species community treatment and the average of the individual species (mixture vs. singlespecies inocula); and third, a comparison of the variation among the three individual fungal species (a two degree of freedom contrast; among AMF species). Because these contrasts are orthogonal and a priori, their tests of significance are not adjusted for multiple comparisons and are not dependent upon the significance of the dissected term in the ANOVA table (Sokal and Rohlf 1995). Comparisons between particular AM fungal species were adjusted for multiple comparisons using Scheffé's method (Sokal and Rohlf 1995).

Final plant biomass.-We analyzed the difference in final biomass produced in absence of herbivory minus biomass produced in the presence of herbivory. Plant tolerance to herbivory is likely a function of storage available at the time of herbivory, and as a result we were interested in changes with reference to storage structures separately from allocation to photosynthetic tissues vs. roots. Thus we calculated the root to shoot ratio excluding the storage structure (the stem or caudex in P. lanceolata [Gleason and Cronquist 1991]) as the ratio of belowground plant mass (roots) to aboveground plant mass (excluding reproductive mass and caudex mass). Reproductive weight consisted of both stalks and flower spikes. Response variables root-to-shoot ratio, and caudex-to-total-plant ratio were arcsine-transformed and plant total mass and reproductive mass were log-transformed to satisfy the normality assumptions of the model. Dependent variables included total plant mass, root to shoot ratio, caudex to total plant ratio, and reproductive mass. Independent variables included block, fungal species, plant genotype, and herbivory. We analyzed plant mass and resource allocation using a mixed-model ANOVA with genotype as a random effect within the general linear models procedure of SAS 2000. In this model, we tested for differences in plant mass and resource allocation between mycorrhizal fungal inoculation treatments using orthogonal a priori linear contrasts within herbivory and herbivory by inoculation terms.

\section{RESUlts}

There were significant differences among mycorrhizal fungal species in their influence on plant performance (among-species-of-inocula contrasts within fungal inocula, Table 1). The effect of herbivory on plant growth rate depended on AM fungal species identity $(P<0.02$, Table 1). Herbivory generally reduced final plant mass, 
and this did not vary greatly among inoculation treatments (herbivory $\times$ fungal inocula, $P>0.05$; Table 1). Mycorrhizal fungal species significantly affected the root-to-shoot ratio of plants (among-species-of-inocula contrasts within fungal inocula, Table 1). There were no overall significant differences between plants associated with different species of mycorrhizal fungi in the caudexto-vegetative-plant-mass ratio (Fig. 3c), and this was due to the variation in the caudex-to-vegetative-plant-mass ratio of plants within the genotypes (genotype $\times$ fungal inocula, Table 1). An additional analysis examining genotypic correlations between the different fungal inocula revealed no patterns in the caudex-to-vegetative-plant-mass ratio. Different mycorrhizal fungal species also resulted in varying allocation to plant reproduction (among species of inocula contrasts within fungal inocula, Table 1). An examination of plant roots in the experiment revealed that all three mycorrhizal species colonized $P$. lanceolata roots both individually and in combination (Bennett 2005).

\section{Response of $\mathrm{P}$. lanceolata associated with Glomus white}

Plants associated with Glomus white experienced a high growth rate (Figs. 1 and 2) and the greatest final biomass (Fig. 3a). The growth rate of plants associated with Glomus white did not change following herbivory (contrasts within herbivory $\times$ fungal inocula; Table 1 , Fig. 2 ) resulting in a reduced final biomass of $P$. lanceolata associated with Glomus white as compared to plants that never experienced herbivory (Fig. 3a). Plants associated with a Glomus white also tended to have a greater root-to-shoot ratio in the absence of herbivory (Fig. 3b). Genotype variation in the ratio of caudex mass to total vegetative plant mass was reduced in plants associated with Glomus white compared to the level of variation found in the majority of other fungal treatments. Reproductive biomass was greatest for plants associated with Glomus white, and herbivory tended to increase reproductive biomass for plants associated with Glomus white (Fig. 3d), although this affect was not significant (herbivory $\times$ fungal inocula, Table 1 ).

\section{Response of $\mathrm{P}$. lanceolata associated with Archaeospora trappei}

Growth promotion for plants associated with Archaeospora trappei was less than growth promotion by Glomus white (Figs. 1 and 3a), however plants associated with $A$. trappei experienced increased growth rates (contrasts within herbivory $\times$ fungal inocula; Table 1 , Fig. 2) following herbivory. As a result, the final biomass of plants hosting $A$. trappei was not significantly affected by herbivory (herbivory $\times$ fungal inocula, Table 1). Plants associated with $A$. trappei tended to have a greater root-to-shoot ratio in the absence of herbivory (Fig. 3b). Two genotypes (D and E) experienced a reduction in the ratio of caudex to vegetative biomass when associated with $A$. trappei, while the majority of the remaining genotypes varied little in allocation to caudex. Herbivory tended to increase reproductive biomass in plants associated with $A$. trappei (Fig. 3d), although this effect was not significant (herbivory $\times$ fungal inocula, Table 1 ).

\section{Response of $\mathrm{P}$. lanceolata associated with Scutelospora calospora}

Plant growth was not promoted by an association with Scutellospora calospora (contrasts within herbivory $\times$ fungal inocula, Fig. 1). In addition, plants associated with $S$. calospora experienced a reduced growth rate following herbivory (contrasts within herbivory $\times$ fungal inocula; Table 1, Fig. 2). Although plant size varies little between plants associated with $S$. calospora that experienced herbivory and those that did not, the relatively small size of these plants may have limited our ability to detect differences between herbivory treatments (Fig. 3a). Some genotypes (such as C and F) had relatively low caudex-to-vegetative-plant-mass ratios in association with $S$. calospora, while others (such as A and $\mathrm{G}$ ) had relatively high ratios resulting in wide variation in genotypic response in the caudex-tovegetative-plant-mass ratio for plants associated with $S$. calospora. Reproduction was not significantly different from zero for plants associated with S. calospora (Fig. $3 d)$.

\section{Response of $\mathrm{P}$. lanceolata associated with a mixture of fungal species}

Plants associated with all three fungal species experienced growth and responses to herbivory similar to those of plants associated with only Glomus white (Figs. 1-4), and significantly greater than the average of the three individual isolates (mixture vs. single species contrast within fungal inocula; Table 1). Plants associated with a mixture of the fungal species experienced the greatest growth (Fig. 2), and herbivory did not affect plant growth rate (contrasts within herbivory $\times$ fungal inocula; Table 1, Fig. 2). Plants associated with a mixture of fungal species had the greatest final biomass, but herbivory reduced final plant biomass (Fig. 3a) as expected from a constant growth rate (Fig. 2). Plants associated with a mixture of mycorrhizal fungal species tended to have a greater root-to-shoot ratio in the absence of herbivory (Fig. 3b), and genotypic variation in the caudex-to-vegetative-biomass ratio was lowest for plants associated with multiple fungal species. Reproductive biomass was greatest for plants associated with a mixture of mycorrhizal fungal species (Fig. 3d), and, in contrast to plants associated with only Glomus white, herbivory tended to reduce reproductive biomass, although this trend was not significant (herbivory $\times$ fungal inocula; Table 1).

\section{DisCUSSION}

\section{Growth and response to herbivory}

Association with each of the fungal species resulted in a different pattern of growth promotion and response to herbivory. P. lanceolata plants associated with Glomus 
TABLE 1. ANOVA results for analyses of growth and final plant mass of Plantago lanceolata.

\begin{tabular}{|c|c|c|c|c|c|c|c|}
\hline \multirow[b]{2}{*}{ Factor } & \multirow[b]{2}{*}{ df } & \multicolumn{2}{|c|}{ Growth rate } & \multicolumn{2}{|c|}{$\log ($ plant mass $)$} & \multicolumn{2}{|c|}{ Root: shoot } \\
\hline & & SS & $P$ & SS & $P$ & SS & $P$ \\
\hline Block & 1 & 0.637 & 0.0003 & 0.304 & 0.0072 & 0.018 & NS \\
\hline Genotype $\dagger$ & 6 & 0.909 & NS & 0.178 & NS & 0.206 & NS \\
\hline Fungal inoculat & 4 & 12.224 & $<0.0001$ & 35.280 & $<0.0001$ & 0.734 & 0.0008 \\
\hline Live inocula vs. sterile inocula & 1 & 1.931 & $<0.0001$ & 10.295 & $<0.0001$ & 0.022 & NS \\
\hline Mixture vs. single-species inocula & 1 & 0.065 & NS & 5.514 & $<0.0001$ & 0.044 & NS \\
\hline Among species of inocula & 2 & 9.470 & $<0.0001$ & 18.401 & $<0.0001$ & 0.668 & $<0.0001$ \\
\hline A. trappei vs. Glomus white & 1 & 3.859 & $<0.0002$ & 2.610 & $<0.0002$ & 0.007 & NS \\
\hline A. trappei vs. S. calospora & 1 & 8.993 & $<0.0002$ & 7.623 & $<0.0002$ & 0.575 & $<0.0002$ \\
\hline Glomus white vs. S. calospora & 1 & 1.709 & $<0.0002$ & 18.351 & $<0.0002$ & 0.491 & $<0.0002$ \\
\hline Herbivory§ & 1 & 0.130 & NS & 0.508 & 0.0352 & 0.008 & NS \\
\hline Genotype $\times$ herbivory & 6 & 0.361 & NS & 0.422 & NS & 0.070 & NS \\
\hline Genotype $\times$ fungal inocula & 24 & 1.880 & 0.0310 & 0.570 & NS & 0.679 & 0.0839 \\
\hline Live inocula vs. sterile inocula & 6 & 0.342 & NS & 0.088 & NS & 0.249 & NS \\
\hline Mixture vs. single-species inocula & 6 & 0.321 & NS & 0.153 & NS & 0.091 & NS \\
\hline Among species of inocula & 12 & 1.217 & 0.0118 & 0.328 & NS & 0.339 & NS \\
\hline Herbivory $\times$ fungal inocula & 4 & 0.413 & 0.0621 & 0.095 & NS & 0.209 & 0.0307 \\
\hline Live inocula vs. sterile inocula & 1 & 0.060 & NS & 0.030 & NS & 0.009 & NS \\
\hline Mixture vs. single-species inocula & 1 & 0.001 & NS & 0.006 & NS & 0.037 & NS \\
\hline Among species of inocula & 2 & 0.335 & 0.0266 & 0.058 & NS & 0.171 & 0.0128 \\
\hline A. trappei vs. Glomus white & 1 & 0.108 & NS & 0.036 & NS & 0.0003 & NS \\
\hline A. trappei vs. S. calospora & 1 & 0.329 & 0.0156 & 0.002 & NS & 0.127 & 0.0212 \\
\hline Glomus white vs. S. calospora & 1 & 0.085 & NS & 0.046 & NS & 0.145 & 0.0128 \\
\hline Error & 76 & 3.251 & & 3.033 & & 1.405 & \\
\hline
\end{tabular}

Notes: Results include sums of squares (SS) and significance $(P)$ for growth rate (calculated on a per-leaf-length basis as the difference in plant size at week 8 and plant size at week 20 divided by plant size at week 8 ), $\log$ of total plant mass, arcsinetransformed root-to-shoot ratio (calculated as ratio of root mass to the total vegetative mass, not including caudex or reproductive mass), arcsine-transformed ratio of storage mass to total vegetative mass (calculated as the ratio of caudex mass to total plant mass excluding reproductive mass), and arcsine-transformed ratio of reproductive mass to total plant mass of Plantago lanceolata at the conclusion of the experiment. Contrasts within the fungal inocula, genotype-by-fungal inocula, and herbivory-by-fungal inocula terms are represented by indentations below their respective term. Non-orthogonal contrasts within the among-species-of-inocula contrasts are represented by additional indentation, and $P$ values were adjusted using Scheffe's method (Sokal and Rohlf 1995:252254). Genotype was considered a random effect, and thus terms were tested across the genotype interaction term. NS indicates not significant.

$\uparrow$ Genotype was tested across genotype $\times$ fungal species and genotype $\times$ herbivory error.

$\$$ Fungal species was tested across genotype $\times$ fungal species error.

$\S$ Herbivory was tested across genotype $\times$ herbivory error.

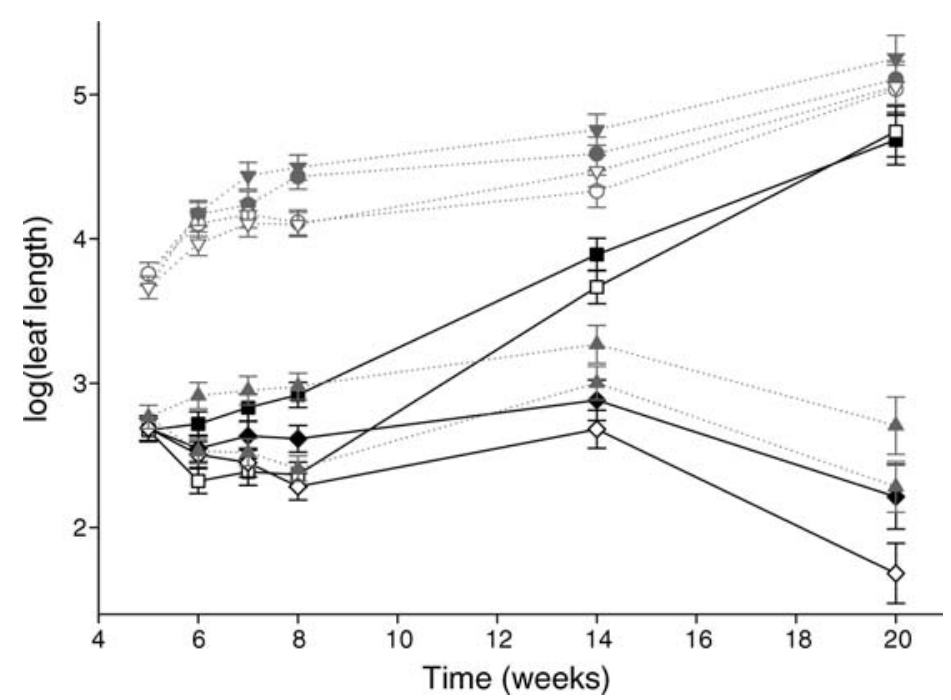

FIG. 1. Aboveground growth rate (as measured by total leaf length, mean \pm SE) of Plantago lanceolata plants associated with one of five mycorrhizal fungal treatments: Glomus white, down-pointing triangles; Archaeospora trappei, squares; Scutellospora calospora, diamonds; a mixture of all three fungi, circles; or sterilized spores of all three fungi, up-pointing triangles; and subjected to two levels of herbivory (no herbivory or three rounds of $20 \%$ defoliation). Solid symbols represent plants that experienced no herbivory, and open symbols represent plants subjected to herbivory. Lines representing plants associated with Archaeospora trappei and Scutellospora calospora have been highlighted in order to better illustrate the contrast between these plants associated with these two fungi. 
TABLE 1. Extended.

\begin{tabular}{|c|c|c|c|}
\hline \multicolumn{2}{|c|}{ Storage : total plant } & \multicolumn{2}{|c|}{ Reproductive } \\
\hline SS & $P$ & SS & $P$ \\
\hline 0.0001 & NS & 1.387 & $<0.0001$ \\
\hline 0.019 & NS & 0.226 & NS \\
\hline 0.097 & 0.0336 & 2.975 & $<0.0001$ \\
\hline 0.083 & $<0.0001$ & 0.883 & $<0.0001$ \\
\hline 0.009 & NS & 0.536 & $<0.0001$ \\
\hline 0.002 & NS & 1.462 & $<0.0001$ \\
\hline 0.001 & NS & 0.283 & 0.0052 \\
\hline 0.0001 & NS & 0.507 & $<0.0002$ \\
\hline 0.001 & NS & 1.462 & $<0.0002$ \\
\hline 0.003 & NS & $7.85 \times 10^{-8}$ & NS \\
\hline 0.010 & NS & 0.111 & NS \\
\hline 0.194 & 0.0070 & 0.496 & NS \\
\hline 0.067 & NS & 0.039 & NS \\
\hline 0.026 & NS & 0.265 & NS \\
\hline 0.100 & NS & 0.000 & NS \\
\hline 0.011 & NS & 0.065 & NS \\
\hline 0.003 & NS & 0.012 & NS \\
\hline 0.0004 & NS & 0.054 & NS \\
\hline 0.009 & NS & 0.001 & NS \\
\hline 0.003 & NS & 0.0002 & NS \\
\hline 0.002 & NS & 0.001 & NS \\
\hline 0.009 & NS & 0.001 & NS \\
\hline 0.289 & & 2.249 & \\
\hline
\end{tabular}

white vs. A. trappei or $S$. calospora experienced the greatest growth promotion (Figs. 1, 2, and 3a), however, an association with Glomus white did not alter plant response to herbivory. Plants associated with Glomus white that experienced herbivory never reached the same size as those that never experienced herbivory (Fig. 3a), and this is supported by the constant growth rate over time regardless of herbivory (Fig. 2). Thus, Glomus white contributed primarily to plant growth, and not to tolerance to herbivory.

A different pattern appeared in plants associated with A. trappei. A. trappei did not prove to be as great a growth promoter as Glomus white (Figs. 1, 2, and 3a), however plants associated with $A$. trappei did benefit from increased plant tolerance to herbivory. Plants associated with $A$. trappei that were subjected to herbivory experienced an increased growth rate (Fig. 2) such that herbivory had no effect on aboveground plant size (Fig. 1) or final plant mass (Fig. 3a). As a result, $A$. trappei contributed less to growth promotion, but more to plant tolerance to herbivory.

Finally, association with $S$. calospora did not enhance growth promotion of $P$. lanceolata (Figs. 1, 2, and 3a), and even appeared to reduce plant growth in the presence of herbivory (Figs. 2 and 3a). An association with $S$. calospora tended to reduce aboveground plant size (Fig. 1), total plant mass (Fig. 3a), and plant growth rate (Fig. 2), while increasing plant allocation to roots (Fig. 3b), thus limiting plant's ability to compensate for herbivore damage. An examination of differences in final biomass (Fig. 3a) would suggest that tolerance to herbivory occurred within plants associated with $S$. calospora or no fungi, however, plant growth rates (Fig. 2) and allocation to reproduction (Fig. 3d) strongly suggest otherwise. In fact, the reduction in plant growth rate with $S$. calospora following herbivory suggests that plants associated with $S$. calospora actually experienced a reduction in tolerance to herbivory. The small mass of these plants likely created a situation in which the variation was great relative to plant size, obscuring any possible differences in plant size that may have occurred in the presence of herbivory. These results suggest that $P$. lanceolata does not benefit, and perhaps suffers a reduction, in growth promotion or tolerance to herbivory in association with $S$. calospora. These results support the role of $S$. calospora in generating negative feedback on the growth of $P$. lanceolata, as previous observations have determined that $S$. calospora is highly competitive on P. lanceolata (Bever 2002, Bennett 2005), and the accumulation of $S$. calospora results in a decline in the P. lanceolata-AM fungal mutualism (Bever 2002).

Plant storage apparently did not play a role in plant tolerance to herbivory. The size of caudices, the storage organs of $P$. lanceolata, did not vary with herbivory. This suggests that either storage in caudices is not important for plant tolerance to herbivory, or that plants could not draw on stored resources to respond to herbivory within a single growing season. Second, all mycorrhizal inocula reduced allocation to caudices (Fig. 3c) (although this allocation was highly dependent on genotype), however tolerance to herbivory increased with one species of mycorrhizae, A. trappei. Thus, this increase in plant tolerance to herbivory with $A$. trappei did not result from a shift in stored resources within the plant, but instead was a direct result of plant association with A. trappei.

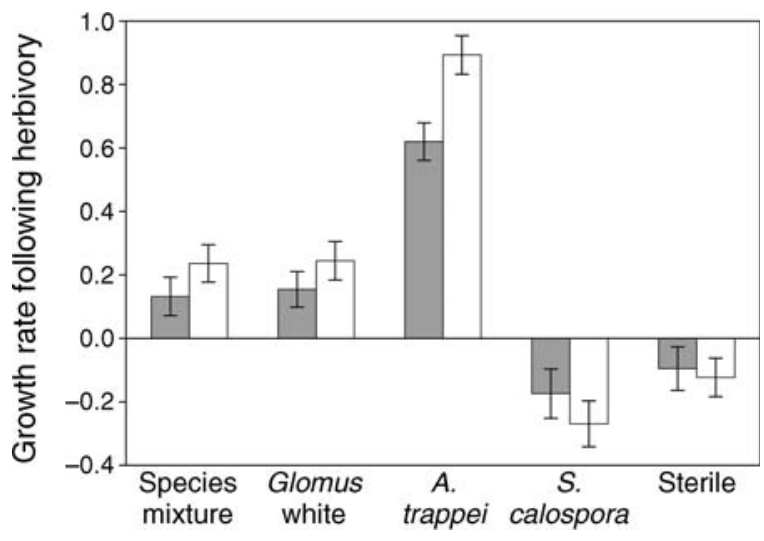

FIG. 2. Growth rate (mean $\pm \mathrm{SE}$ ) of plants subjected to herbivory (open bars) and those that did not experience herbivory (gray bars) after three rounds of $20 \%$ defoliation by common buckeye butterfly larvae. Growth rates were calculated using the difference between total leaf length at week 8 (one week following the last defoliation event) and total leaf length at week 20 weighted by total leaf length at week 8 . Differences in growth rate varied for plants associated with Archaeospora trappei and Scutellospora calospora. 

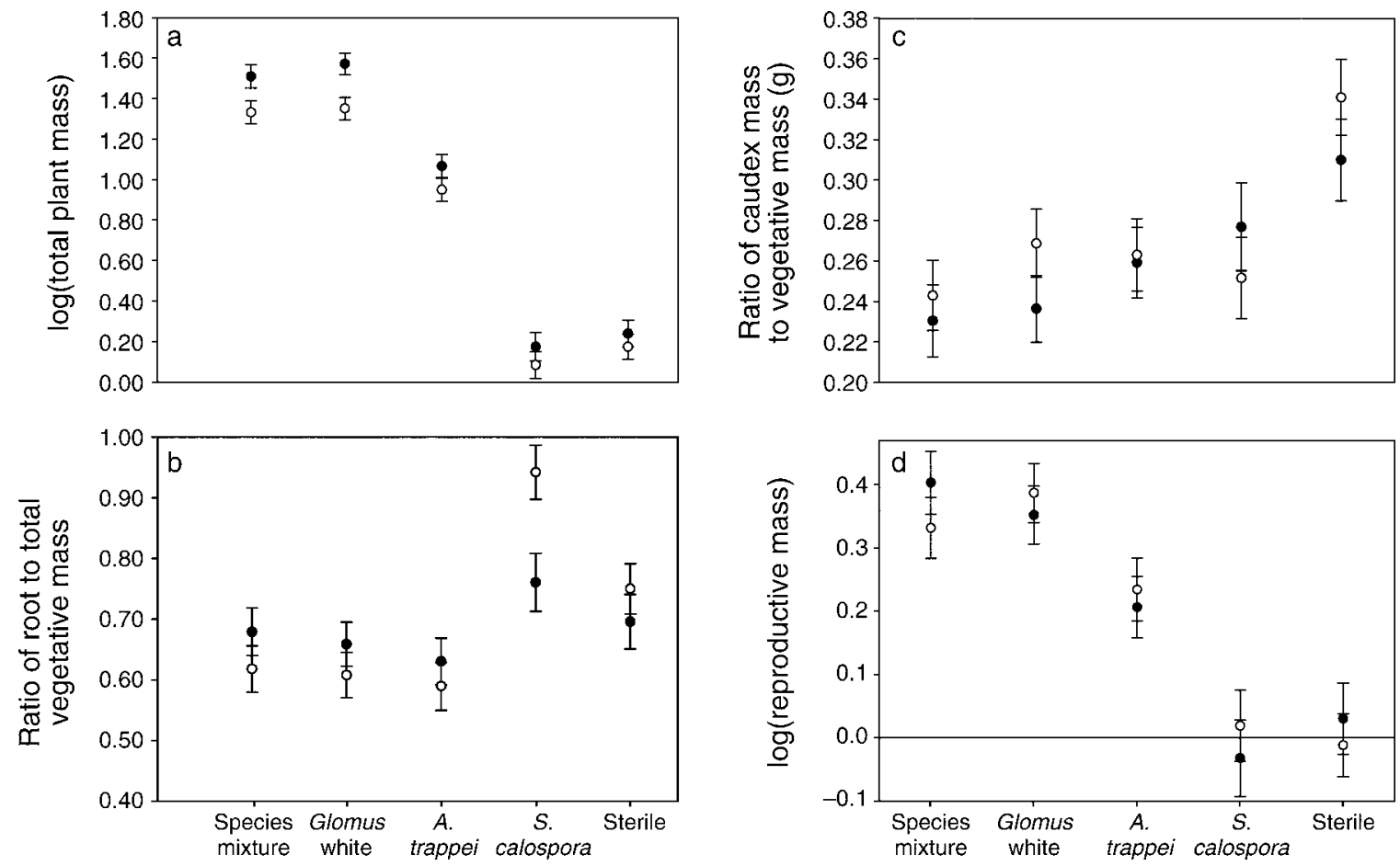

FIG. 3. Representations of final biomass of plants associated with five different fungal inocula. Plants that did not experience herbivory are represented by solid circles, and plants subjected to herbivory are represented by open circles. Error bars represent \pm SE. (a) Least-square means of the log of total dry mass of plants grown with all possible fungal combinations. (b) Root-to-shoot ratio calculated by dividing total root mass by total plant mass (not including storage or reproductive mass). (c) Ratio of storage (caudex) mass to total plant mass (not including reproductive mass). (d) Log of reproductive mass.

Examinations of plant tolerance in the presence of mycorrhizal fungi have demonstrated no tolerance (Borowicz 1997, Gange et al. 2002, Kula et al. 2005), tolerance (Gange et al. 2002, Kula et al. 2005), and increased tolerance (Kula et al. 2005) to herbivory in final plant biomass. These studies have focused primarily on final plant mass (but see Borowicz 1997), thus ignoring changes in plant growth rates and resource allocation to roots, storage, and reproduction that are likely to vary following herbivory, as shown here. In final biomass, the non-mycorrhizal Senecio jacobaea showed no tolerance to herbivory in the presence of mycorrhizal fungi (Gange et al. 2002). In contrast, a community of mycorrhizal fungi contributed to tolerance (measured as final biomass) in a tallgrass prairie microcosm, and this effect was primarily driven by the increased tolerance of two warm-season grasses (Andropogon gerardii and Sorghastrum nutans) and a legume (Lespedeza capitata; Kula et al. 2005). An examination of Plantago lanceolata revealed no difference in final aboveground biomass between mycorrhizal plants in the field that did and did not experience herbivory, thus suggesting tolerance (Gange et al. 2002) similar to that of plants associated with $A$. trappei in this experiment. In contrast, in this experiment, tolerance to herbivory by Plantago lanceolata was dependent upon the fungal species present (Fig.
3). Thus, as demonstrated in this study, plant response to herbivory is likely to depend on the species of mycorrhizae with which a host plant associates.

Nonadditive effects of mycorrhizal fungi on plant growth

Given the response of host plants to each fungal species individually, we can make several predictions for

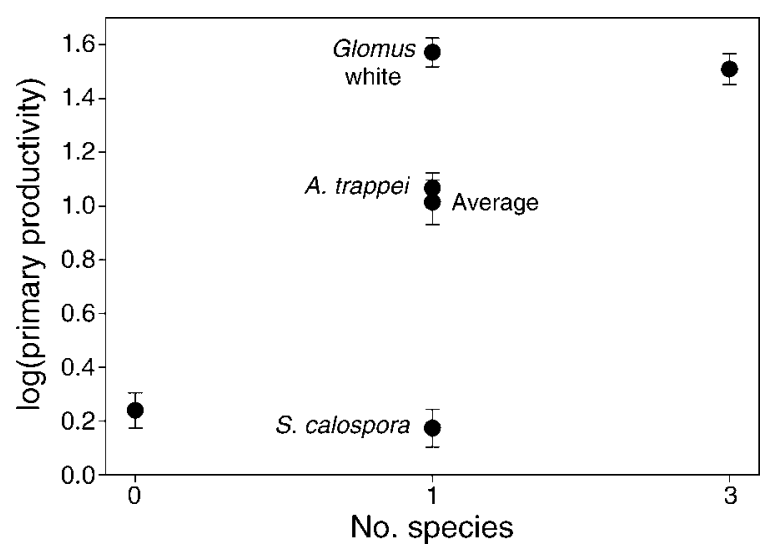

FIG. 4. Plant productivity vs. diversity of fungal species $(0$, 1, or 3 species) associated with Plantago lanceolata. The average growth with each fungal species individually has been added as a reference point within the single-species diversity group. Error bars represent $\pm \mathrm{SE}$. 
how they would behave in combination. First, growth promotion of $P$. lanceolata associated with all three fungal species may be the average of growth promotion of $P$. lanceolata when grown alone with each fungal species. We would expect this result if each fungal species contributed equally to the growth of $P$. lanceolata in proportion to the area of root they colonize (and competition among fungal species did not alter proportional colonization). For example, growth promotion of strawberry plants (Fragaria $\times$ ananassa) associated with two species of Glomus was the average of growth promotion of strawberry by each fungus individually (Gange 2001), suggesting that both species of Glomus contribute equally to strawberry growth with respect to the area of root they colonize. In this study, if growth promotion was averaged with respect to the respective proportion of initial inocula, growth of $P$. lanceolata associated with all three fungal species would have been lower than that demonstrated (Fig. 4), thus not supporting this possibility.

Alternatively, growth promotion of $P$. lanceolata may increase with each additional species of mycorrhizal fungi with which it associates (van der Heijden et al. 1998). We would expect this result if each fungal species contributed equally to the growth of $P$. lanceolata regardless of how much root space they occupy. Thus, each fungal species would increase plant growth in a manner similar to that when grown alone despite a reduction in root colonization due to competition with other fungi. For example, Bromus inermis associated with three different Glomus species experienced greater growth promotion than Bromus inermis plants associated with only one of the three fungal species (Klironomos et al. 2004), suggesting that all three species of Glomus contributed equally to the growth of Bromus inermis despite the potential reduction in per species fungal colonization due to fungal competition. In this experiment, if growth promotion increased with each successive species of fungi added we would expect to see growth promotion of plants associated with all three fungal species to be greater than that of Glomus white alone, however this is not the case.

Finally, growth promotion of $P$. lanceolata could be driven by a sampling effect, or the probability of including a "super fungus" whose growth promotion properties exceed that of other included species (Wardle 1999). This would occur if each species within a combination did not contribute equally to the growth of $P$. lanceolata. An examination of growth rate (Fig. 2) and final biomass (Fig. 3) showed that P. lanceolata plants associated with all three fungal species achieved the same level of biomass as those associated with only Glomus white, and experienced greater growth promotion and little tolerance to herbivory. Thus, in this system plant biomass, or primary productivity, is driven by a sampling effect, or the inclusion of the dominant fungus Glomus white.

\section{Implications}

This study demonstrated species specific host responses to mycorrhizal fungi in growth promotion and plant response to herbivory. Each fungal species promoted a different pattern of growth and plant tolerance: Glomus white promoted growth within plant hosts, A. trappei promoted growth (at a reduced level) and plant tolerance to herbivory, and $S$. calospora did not promote host growth and tended to reduce plant tolerance to herbivory. A mixture of all three fungal species resulted in growth and tolerance patterns similar to plants associated with Glomus white. These results suggest that both growth promotion and plant tolerance are likely to vary with the presence of different mycorrhizal species.

The similarities in growth response and plant tolerance to herbivory between plants associated with Glomus white and a mixture of all three fungal species suggests that the sampling effect, or the probability of including a "super fungus" in higher diversity treatments, explains growth and tolerance patterns within $P$. lanceolata hosts associated with multiple fungi. The presence of a single mycorrhizal fungal species driving much of the growth response of a plant species has important implications for plant establishment in various habitats. Plants establishing in areas that lack the fungus best at promoting their growth may suffer in competitive interactions with neighboring plants and may even be eliminated from a community.

In this study, we found a complex species-specific interaction involving multiple trophic levels, suggesting that community dynamics are likely products of multiple indirect interactions leading to several possible outcomes. This study is the first to examine individual mycorrhizal fungal responses in a multitrophic community. There is much work still to be done teasing apart how mycorrhizal fungi might alter aboveground interactions in both spatial and species specific contexts.

\section{ACKNOWLEDGMENTS}

We thank David McNutt, Julie Gummow, Dacia Montemayor, Alex Nguyen, Tommy Zajac, Deane Bowers, Lisa Pratt, Simon Brassel, and David Finkelstein for assistance with data collection, protocols, and equipment. We thank Fred Nijhout, Laura Grunert, and Deane Bowers for providing Junonia coenia butterflies, and for help caring for them. We thank Keith Clay, Heather Reynolds, Curt Lively, Peggy Schultz, Scott Mangan, Tom Platt, Jennifer Rudgers, Rick Lankau, Mirka Macel, and the Bever/Schultz lab group for taking the time to review and discuss this paper with us. We also acknowledge the support of Sigma Xi Grant-In-Aid of Research, Indiana University McCormick Grant, and NSF grants DEB-0407816 to Alison Bennett and DEB-0049080 to Jim Bever.

\section{Literature Cited}

Bennett, A. E. 2005. Mechanisms underlying complex interactions between plants, herbivores, and arbuscular mycorrhizal fungi. Indiana University, Bloomington, Indiana, USA.

Bennett, A. E., J. Alers-Garcia, and J. D. Bever. 2006. Threeway interactions among mutualistic mycorrhizal fungi, plants, and plant enemies: hypotheses and synthesis. American Naturalist 167:1-136. 
Bever, J. D. 1994. Feedback between plants and their soil communities in an old field community. Ecology 75:19651977.

Bever, J. D. 2002. Negative feedback within a mutualism: hostspecific growth of mycorrhizal fungi reduces plant benefit. Proceedings of the Royal Society of London Series BBiological Sciences 269:2595-2601.

Bever, J. D., J. B. Morton, J. Antonovics, and P. A. Schultz. 1996. Host-dependent sporulation and species diversity of arbuscular mycorrhizal fungi in a mown grassland. Journal of Ecology 84:71-82.

Bever, J. D., P. A. Schultz, A. Pringle, and J. B. Morton. 2001. Arbuscular mycorrhizal fungi: more diverse than meets the eye, and the ecological tale of why. BioScience 51:923-931.

Bobbitt, J. M., and K. P. Segebarth. 1969. Iridoid glycosides and similar substances. Pages 1-145 in W. I. Taylor and A. R. Battersby, editors. Cyclopentanoid terpene derivatives. Marcel Dekker, New York, New York, USA.

Borowicz, V. A. 1997. A fungal root symbiont modifies plant resistance to an insect herbivore. Oecologia 112:534-542.

Bowers, M. D., and S. K. Collinge. 1992. Fate of iridoid glycosides in different life stages of the buckeye, JunoniaCoenia (Lepidoptera, Nymphalidae). Journal of Chemical Ecology 18:817-831.

Bowers, M. D., and G. M. Puttick. 1986. Fate of ingested iridoid glycosides in lepidopteran herbivores. Journal of Chemical Ecology 12:169-178.

Charron, G., V. Furlan, M. Bernier-Cardou, and G. Doyon. 2001. Response of onion plants to arbuscular mycorrhizae 1 . Effects of inoculation method and phosphorus fertilization on biomass and bulb firmness. Mycorrhiza 11:187-197.

Duff, R. B., J. S. D. Bacon, C. M. Mundie, V. C. Farmer, J. D. Russell, and A. Forreste. 1965. Catalpol and methylcatalpol: naturally occurring glycosides in Plantago and Buddleia species. Biochemical Journal 96:1-5.

Gange, A. C. 2001. Species-specific responses of a root- and shoot-feeding insect to arbuscular mycorrhizal colonization of its host plant. New Phytologist 150:611-618.
Gange, A. C., E. Bower, and V. K. Brown. 2002. Differential effects of insect herbivory on arbuscular mycorrhizal colonization. Oecologia 131:103-112.

Gange, A. C., V. K. Brown, and D. M. Aplin. 2005. Ecological specificity of arbuscular mycorrhizae: evidence from foliarand seed-feeding insects. Ecology 86:603-611.

Gleason, H. A., and A. Cronquist. 1991. Manual of vascular plants of Northeastern United States and adjacent Canada. Second edition. New York Botanical Garden, New York. New York, USA.

Karban, R., and I. T. Baldwin. 1997. Induced responses to herbivory. University of Chicago Press, Chicago, Illinois, USA.

Klironomos, J., J. McCune, and P. Moutoglis. 2004. Species of arbuscular mycorrhizal fungi affect mycorrhizal responses to simulated herbivory. Applied Soil Ecology 26:133-141.

Kula, A. A. R., D. C. Hartnett, and G. W. T. Wilson. 2005. Effects of mycorrhizal symbiosis on tallgrass prairie plantherbivore interactions. Ecology Letters 8:61-69.

SAS Institute. 2000. SAS 2000. SAS Institute, Cary North Carolina, USA.

Smith, S. E., and D. J. Read. 1997. Mycorrhizal symbiosis. Second edition. Academic Press, London, UK.

Sokal, R. R., and F. J. Rohlf. 1995. Biometry. Third edition. W. H. Freeman and Company, New York, New York, USA. Vandenkoornhuyse, P., K. P. Ridgway, I. J. Watson, A. H. Fitter, and J. P. W. Young. 2003. Co-existing grass species have distinctive arbuscular mycorrhizal communities. Molecular Ecology 12:3085-3095.

van der Heijden, M. G. A., J. N. Klironomos, M. Ursic, P. Moutoglis, R. Streitwolf-Engel, T. Boller, A. Wiemken, and I. R. Sanders. 1998. Mycorrhizal fungal diversity determines plant biodiversity, ecosystem variability and productivity. Nature 396:69-72.

Wardle, D. A. 1999. Is "sampling effect" a problem for experiments investigating biodiversity-ecosystem function relationships? Oikos 87:403-407. 